a follow up of one year $(n=21), 2$ years $(n=11)$, and 3 years $(n=5)$. A reduction in the daily median dose of prednisone from $10 \mathrm{mg}[0-15 \mathrm{mg}]$ to $0[0-0 \mathrm{mg}] \mathrm{in}$ 3 years, $(p<0.05)$ was observed. After a median follow-up of $20.5 \pm 11.7$ months in 4 patients, the interval between TCZ doses was increased to 5 weeks $(n=2)$, 6 weeks (1) and 7 weeks (1) because of remission. TCZ had to be withdrawn due to articular inefficiency (1) or articular and ocular inefficiency (1). The main adverse effects were severe autoimmune thrombocytopenia, autoimmune anemia and thrombocytopenia, pneumonia, viral conjunctivitis and bullous impetigo in 1 patient each.

Conclusions: TCZ is useful at short and long term follow-up for severe Juvenile Idiopathic Arthritis-associated uveitis. It is possible to optimize the TCZ dose.

Disclosure of Interest: None declared

DOI: 10.1136/annrheumdis-2017-eular.5265

\section{THU0527 PEDIATRICIAN AND ADULT RHEUMATOLOGIST COLLABORATING IN A MULTIDISCIPLINARY REUMA-PED CLINIC. IS THIS TRANSITIONAL CARE MODEL EFFECTIVE?}

P. Collado ${ }^{1}$, A. Rubio ${ }^{1}$, R. Diaz-Delgado ${ }^{2}$, C. Calvo ${ }^{2}$, R. Mustienes ${ }^{1}$, F. Rey $^{1}$ C. Bonilla ${ }^{1}$, E. Cruz ${ }^{1}$. ${ }^{1}$ Rheumatology; ${ }^{2}$ Pediatric, Hospital Universitario Severo Ochoa, Madrid, Spain

Background: Transitional care should be a planned movement of adolescents with chronic diseases from child-centred to adult-oriented health care system. Recently a EULAR/PReS taskforce has developed the first international set of recommendations and standards for transitional care ${ }^{1}$

Objectives: To describe the results from a specific transitional care programme. Methods: The current transitional care programme includes a multidisciplinary PED-REUMA clinic (MPRC) weekly and a non-defined period of rheumatologic follow-ups by the same rheumatologist of MPRC. The transitional care team is composed of two pediatricians, one adult rheumatologist -as transition coordinator, a clinical nurse specialist and administrative support, as well as a psychologist and physiotherapists. Clinical information and therapies were collected throughout the disease course, and the HEADSS method of psychosocial interviewing has been included recently.

Population of the present study included young patients (YP) from that programme who are going to transfer to adult-oriented health care system. Descriptive study of socio-demographics and clinic features was included, as well as patients' adherence. YP confidence to be transferred and satisfaction with the current transitional process were measured using on a scale of 0 to 10 . In patients suffering from juvenile idiopathic arthritis (JIA), clinical status of disease activity and clinical remission and $\mathrm{CHAQ}$ were tested before transfer.

Results: Twenty-seven YP with female predominance (63\%) were included. The average age was $21 \pm 3$ yo at time of a planned transfer and $16 \pm 3.4$ yo at inclusion to the MPRC. JIA was the commonest condition whereas dermatomyositis was uncommon. Up to $63 \%$ patients required some DMARDs during the MPRC follow-up, but only a 37\% needs maintained immunosuppressive therapies and three $(11 \%)$ patients required changing the therapeutic target before transfer. YP adherence to rheumatologist appointments was high. Regarding HEADSS data: most YP were students and living at family home, around $50 \%$ gave up sports or other activities due to homework or exams, $29 \%$ of YP occasionally drank some alcohol but none used tobacco, and $47 \%$ of YP felt sad or down once in a while. Patient's confidence to be transferred was $7.7 \pm 2.1$ (mean $\pm S D$; min-max: $2-10)$. YP showed high satisfaction with the current transitional process, $9.7 \pm 0.4$ (min-max: 9-10)

Before transfer, 17 patients with JIA showed a mean \pm SD value of JADAS10 of $2 \pm 5$ (min-max, $0-18$ ), clinical remission on/off medication was $23 \%$ and $53 \%$ respectively. Mostly functional status reported by patient was low, YP-rated CHAQ (mean 0.06; min-max, 0.0-0.75).

Conclusions: To the best of our knowledge, this is the first study evaluating a Spanish transitional care programme. The study reports a positive impact across adolescence of our transitional care model in a real life situation. Implementation of recommendations depended on the local available resources.

[1] Foster HE. EULAR/PReS standards and recommendations for the transitional care of young people with juvenile-onset rheumatic diseases. Ann Rheum Dis Published Online First: [1, November 2016] doi:10.1136/ annrheumdis-2016210112.

Acknowledgements: Beatriz Jimenez. Auxiliary to the clinical nurse specialist and administrative support of Rheumatology Department.

Disclosure of Interest: None declared

DOI: 10.1136/annrheumdis-2017-eular.5444

\section{THU0528 STING-ASSOCIATED VASCULOPATHY WITH ONSET IN INFANCY (SAVI): A DIFFERENTIAL DIAGNOSIS OF INFLAMMATORY INTERSTITIAL LUNG DISEASE}

$\underline{\text { R. Dagher }}{ }^{1}$, R. Ghiye ${ }^{1}$, G. Nicolas ${ }^{1}$, H. Feghali ${ }^{1}$, M.C. Fadous Khalife ${ }^{1}$, L. Seabra ${ }^{2}$, Y.J. Crow ${ }^{2}$. 1 Pediatrics, Notre Dame de Secours University Hospital, Byblos, Lebanon; ${ }^{2}$ Paris-Descartes University, Sorbonne-Paris-Cite, Institut Imagine, INSERM UMR 1163, Paris, France

Background: STING-Associated Vasculopathy with onset in Infancy (SAVI) is an auto-inflammatory monogenic disease. SAVI is caused by an upregulation of type I interferon signaling due to sporadic or inherited gain-of-function mutations in the STimulator of INterferon Gene (STING)/Transmembrane Protein 173 (TMEM173) The first description of this phenotype, and the identification of the mutated gene was in 2014. SAVI is characterized mainly by cutaneous vasculopathy leading to necrotic lesions, and progressive interstitial lung disease with secondary fibrosis. Objectives: SAVI is a rare disease with unknown prevalence. To the best of our knowledge, 25 cases have been reported so-far. These patients variably manifest cutaneous lesions and inflammatory lung disease. Here we present a case of SAVI with onset of features at the age of 3 years.

Methods: A now 8 year old boy born to non-consanguineous parents was described to have experienced recurrent fevers, polyarthralgia and polyarthritis, livedo of the limbs, facial telangiectasia, necrotic lesions of auricles and digits and failure to thrive since the age of 3 years. He has normal cognitive development. His familial history is notable for epilepsy in 2 of his siblings and Behcet disease in a paternal cousin.

Laboratory tests at age 6.5 years revealed increased ESR $(60 \mathrm{~mm} / \mathrm{h})$ while CRP varied from 3 to $14 \mathrm{mg} / \mathrm{L}$. ANA titres were positive (1/640), with normal complement level and negative anti-DNA. c-ANCA and p-ANCA were negative. $\mathrm{ECA}$ and lysozymes were in the normal range. Although the child had no respiratory symptoms, chest $\mathrm{X}$-ray revealed diffuse interstitial parenchymal infiltrates. Chest angio-CT showed ground-glass lesions with fibrotic bands and mediastinal and para-hilar adenopathies. FVC and DLCO were reduced on pulmonary functional testing. Lung biopsy was not performed.

Empirical treatment with pulse and oral corticosteroids along with azathioprine was started. Over a period of one year, systemic inflammation and skin involvement regressed dramatically, but his lung disease showed no improvement.

Results: Genetic testing identified a previously reported V155M mutation in TMEM173.

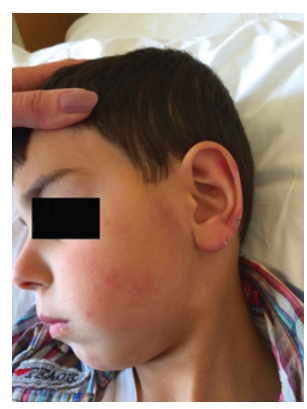

Conclusions: SAVI is associated with significant morbidity and mortality. The diagnosis should be considered in children with interstitial lung disease after more common causes have been ruled out. Steroids and immunosuppressive therapies apparently show no efficacy in avoiding progression to irreversible lung damage. Promising results with treatment by Janus Kinase inhibitors as a means of blocking signaling downstream of the type I interferon receptor were recently published.

References:

[1] Y. Liu, A.A. Jesus, B. Marrero, et al. Activated STING in a vascular and pulmonary syndrome. N Engl J Med, 371 (2014), pp. 507-518.

[2] N. Jeremiah, B. Neven, M. Gentili, et al. Inherited STING-activating mutation underlies a familial inflammatory syndrome with lupus-like manifestations. J Clin Invest, 124 (2014), pp. 5516-5520.

[3] Fremond ML, Rodero MP, et al. Efficacy of the Janus Kinase 1/2 inhibitor ruxolitinib in the treatment of vasculopathy associated with TMEM173activating mutations in 3 children. J Allergy Clin Immunol. 2016 Dec; 138(6): 1752-1755.

Acknowledgements: We thank Isabelle Melki for her valuable assistance in this case.

Disclosure of Interest: None declared

DOI: 10.1136/annrheumdis-2017-eular.4489

\section{THU0529 METHOTREXATE TREATMENT RESPONSE IN NON-SYSTEMIC JUVENILE IDIOPATHIC ARTHRITIS}

R. Bakry, G. Horneff. Asklepios, Sankt Augustin, Germany

Background: Methotrexate is approved and recommend as first line disease modifying antirheumatic drug (DMARD) in polyarticular juvenile idiopathic arthritis (JIA). In can be used orally or via s.c. injection.

Objectives: S.c MTX is thought to be more efficious or act more rapidly than oral MTX. Thus we want to analyse the kinetic of response in JIA patients treated with oral versus s.c. MTX.

Methods: In the German BIKER registry a cohort of biologics naïve JIA patients starting treatment with MTX was built. The data bank was screened for patients treated with MTX orally vs. s.c for the first time. The JIA-ACR 90 and the JADAS10 definition of remission were used as outcome parameters.

Results: $410 \mathrm{JIA}$ patients received treatment with oral MTX and 384 received s.c. MTX. RF negative polyarthritis was the most common JIA category $(50 \% / 51 \%)$ 